\title{
Pengaruh Budaya Organisasi dan Kepuasan Kerja Terhadap Kinerja Karyawan dan Komitmen Organisasi Sebagai Variabel Mediasi Pada PT Tiki Jalur Nugraha Ekakurir Jakarta
}

\author{
Stella Karunia Avera dan M. Tony Nawawi \\ Fakultas Ekonomi Universitas Tarumanagara Jakarta \\ Email : stella_avera@yahoo.com
}

\begin{abstract}
The purpose of this study was to determine the effect of organizational culture and job satisfaction on employee performance and organizational commitment as mediation. The method in this study uses descriptive research with a quantitative approach and using questionnaires as a data collection tool. The population in this study were all employees working in the service sector at PT Tiki Jalur Nugraha Ekakurir (JNE) Jakarta. The sample size used in this study was 100 respondents. This study uses SmartPLS version 3.2.8. The results of this study indicate that (1) organizational culture has a positive and significant effect on employee performance (2) job satisfaction has a positive and significant effect on employee performance (3) organizational culture has a positive and significant but not direct effect on employee performance and organizational commitment as mediation variables (4) organizational culture has a positive and significant effect on employee performance (5) organizational commitment has a positive and significant effect on employee performance.
\end{abstract}

Keywords: organizational culture, job satisfaction, employee performance, organizational commitment

\begin{abstract}
Abstrak: Tujuan dari penelitian ini adalah untuk mengetahui pengaruh budaya organisasi dan kepuasan kerja terhadap kinerja karyawan dan komitmen organisasi sebagai varibel mediasi. Metode pada penelitian ini mengunakan penelitian deskriptif dengan pendekatan kuantitatif dan mengunakan kuisioner sebagai alat pengumpulan data. Populasi dalam penelitian ini adalah semua karyawan yang bekerja dalam bidang jasa di PT Tiki Jalur Nugraha Ekakurir (JNE) Jakarta. Ukuran sampel yang digunakan pada penelitian ini sebanyak 100 responden. Penelitian ini menggunakan SmartPLS versi 3.2.8. Hasil pada penelitian ini menunjukkan bahwa (1) budaya organisasi berpengaruh positif dan signifikan terhadap kinerja karyawan (2) kepuasan kerja berpengaruh positif dan signifikan terhadap kinerja karyawan (3) budaya organisasi berpengaruh positif dan signifikan tetapi tidak secara langsung terhadap kinerja karyawan dan komitmen organisasi sebagai varibel mediasi (4) budaya organisasi berpengaruh positif dan signifikan terhadap kinerja karyawan (5) komitmen organisasi berpengaruh positif dan signifikan terhadap kinerja karyawan.
\end{abstract}

Kata kunci: budaya organisasi, kepuasan kerja, kinerja karyawan, komitmen organisasi 


\section{LATAR BELAKANG}

Kondisi perekonomian Indonesia saat ini berkembang menjadi semangkin baik dalam era globalisasi. Seluruh perusahaan berperan aktif dalam pertumbuhan global perekonomian Indonesia serta dapat bersaing didalam segi operasional maupun koseptual. Jasa pengiriman barang berkembang cukup pesat saat ini . Adanya beberapa perusahaan baru yang bergerak dalam bidang industri jasa pengiriman. Seiring dalam peningkatan aktivitas pengiriman logistic maka berkembang juga bisnis e-commerce seperti Tokopedia, Shoope,Bukalapak, Bli bli, OLX.

Kinerja karyawan memegang peranan sebagai media untuk melancarkan pelaksanaan kegiatan usaha. Peran yang handal dan profesional dalam usaha meningkatkan kinerja sangat dibutuhkan, karena akan mempengaruhi kelangsungan organisasi. Seorang karyawan akan memiliki kinerja kerja yang tinggi apabila mendapatkan kesimbangan antar kemampuan yang dimiliki dengan pekerjaan yang dikerjakan maka akan timbul tanggung jawab dalam dirinya untuk menyelesaikan tugasnya secara maksimal.

Budaya yang kuat akan mempunyai pengaruh yang besar pada perilaku anggotaanggotanya karena tingginya tingkat kebersamaan dan intensitas menciptakan suatu iklim internal dari kendali perilaku yang tinggi. Perilaku karyawan dipengaruhi oleh lingkungan sekitar tempat mereka bekerja jika ditempat mereka bekerja memiliki sifat atau perilaku yang positif maka hubungan antar karyawan. Menjadi lebih baik dan positif.

Kepuasan kerja mencerminkan perasaan seseorang terhadap pekerjaan yang dikerjaannya yang berdampak positif terhadap pekerjaan yang dilakukannya dan segala sesuatu yang dihadapi dilingkungan perusahannya. Saat melakukan pekerjaan harus mempunyai komitment yang kuat agar tugas yang ditetepkan dapat berjalan dengan baik. Jika seorang individu tidak mempunyai komitment akan melakukan tindakan yang tidak menyenangkan yang dapat menimbulkn kesan buruk bagi dirinya sendiri

\section{Perumusan masalah}

1. Apakah budaya organisasi berpengaruh positif dan signifikan terhadap kinerja karyawan PT Tiki Jalur Nugraha Ekakurir (JNE) ?

2. Apakah kepuasan kerja berpengaruh positif dan signifikan terhadap kinerja karyawan PT Tiki Jalur Nugraha Ekakurir (JNE) ?

3. Apakah budaya organisasi berpengaruh positif dan signifikan terhadap kinerja karyawan dan komitment organisasi sebagai variable mediasi PT Tiki Jalur Nugraha Ekakurir (JNE) Jakarta ?

4. Apakah budaya organisasi mempunyai pengaruh yang positif dan signifikan terhadap kepuasan kerja PT Tiki Jalur Nugraha Ekakurir (JNE) Jakarta ?

5. Apakah komitment organisasi mempunyai pengaruh yang positif dan signifikan terhadap kinerja karyawan PT Tiki Jalur Nugraha Ekakurir (JNE) Jakarta ?

\section{Tujuan penelitian}

1. Untuk mengetahui budaya organisasi berpengaruh positif dan signifikan terhadap kinerja karyawan PT Tiki Jalur Nugraha Ekakurir (JNE) 
2. Untuk mengetahui kepuasan kerja berpengaruh positif dan signifikan terhadap kinerja karyawan PT Tiki Jalur Nugraha Ekakurir (JNE) Jakarta

3. Untuk mengetahui budaya organisasi mempunyai pengaruh yang positif dan signifikan terhadap kinerja karyawan dan komitmen organisasional sebagai variavle mediasi PT Tiki Jalur Nugraha Ekakurir (JNE) Jakarta

4. Untuk mengetahui budaya organisasi mempunyai pengaruh yang positif dan signifikan terhadap kepuasan kerja PT Tiki Jalur Nugraha Ekakurir (JNE) Jakarta

5. Untuk mengetahui komitment organisasional mempunyai pengaruh yang positif dan signifikan terhadap kinerja karywan PT Tiki Jalur Nugraha Ekakurir (JNE) Jakarta

\section{KAJIAN TEORI}

Menurut Rivai dan Mulyadi (2012) budaya organisasi adalah suatu kerangka kerja yang menjadi pedoman tingkah laku seharihari dan membuat keputusan untuk karyawan dan mengarahkan tindakan mereka untuk mencapai tujuan organisasi. Menurut Marta dan Suharnomo (2011) budaya organisasi adalah nilai-nilai dan simbol-simbol yang dipahami dan ditaati bersama-sama oleh semua anggota organisasi. Budaya ini unik milik organisasi tertentu sebagai pembeda antara organisasi kepada orang lain.

Menurut Mangkunegara (2012) kepuasan kerja adalah suatu perasaan yang menyokong atau tidak menyokong diri pegawai yang berhubungan dengan pekerjaannya maupun dengan kondisi dirinya.

Menurut Taurisa dan Ratnawati (2012) kinerja karyawan merupakan hasil kerja secara kualitas maupun kuantitas yang dicapai oleh seseorang dalam melaksanaka tugas yang diberikan kepadanya sesuai dengan standar atau kriteria yang telah ditetapkan. Kinerja menunjukan tingkat keberhasilan keryawan dalam melaksanakan tugas dan tanggung jawabnya. Semakin tinggi kinerja karyawan, maka produktivitas organisasi secara keseluruhan akan meningkat.

Menurut Mathis dan Jackson (2010) komitmen organisasi adalah di mana karyawan yakin dan menerima tujuan organisasional, serta berkeinginan untuk tinggal bersama organisasi tersebut. Kreitner dan Kinicki (2014) komitmen organisasi adalah tingkatan dimana seseorang mengenali sebuah organisasi dan terikat pada tujuan-tujuannya. 
Gambar 1. Model Penelitian

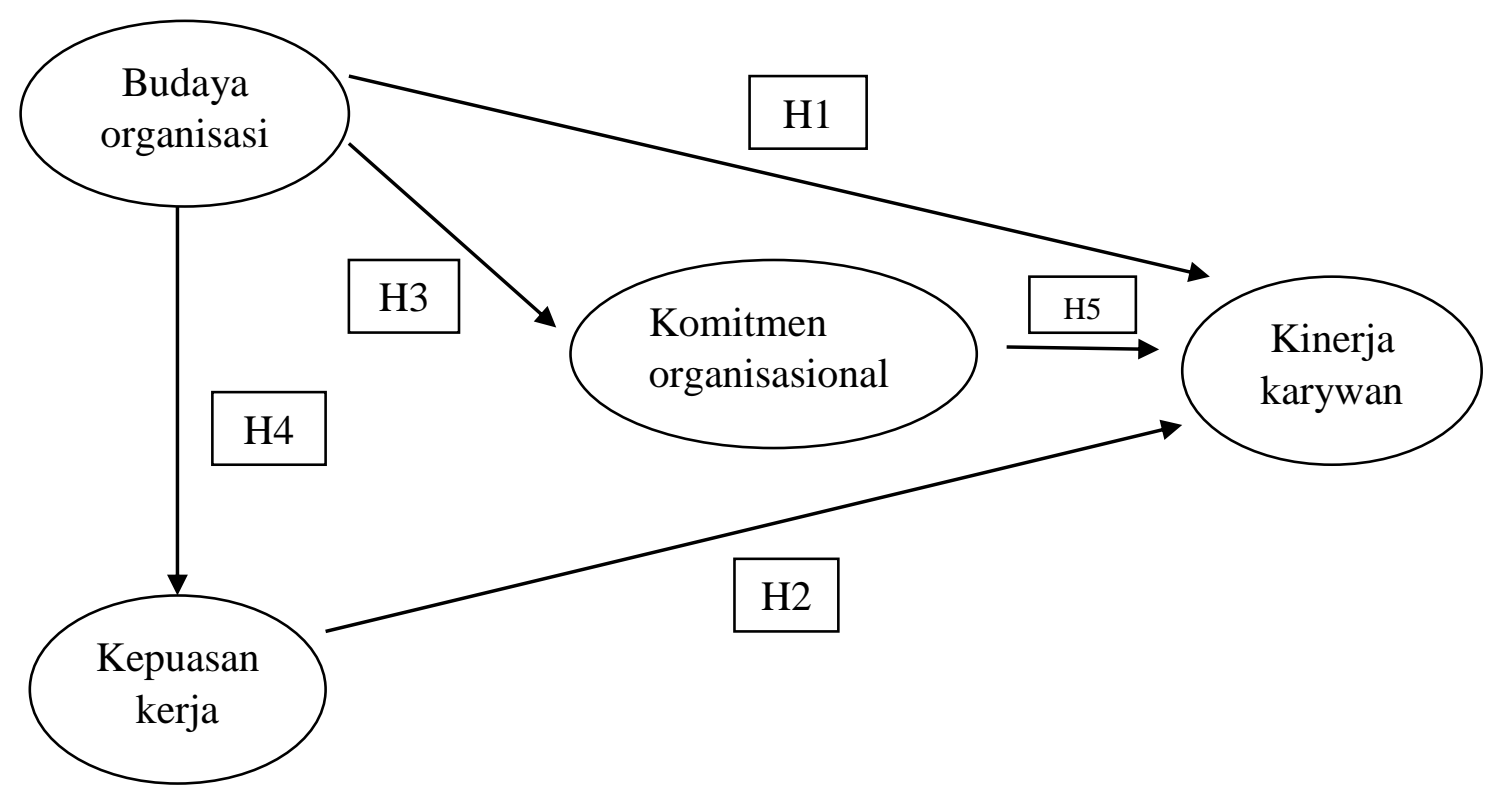

Berdasarkan landasan teori dan kerangka pemikiran yang dijelaskan diatas maka hipotesis yang dapat dibentuk adalah:

1. H1: Budaya organisasi mempunyai pengaruh yang positif dan signifikan terhadap kinerja karyawan PT Tiki Jalur Nugraha Ekakurir (JNE) Jakarta

2. H2: Kepuasan kerja mempunyai pengaruh yang positif dan signifikan terhadap kinerja karywan PT Tiki Jalur Nugraha Ekakurir (JNE) Jakarta

3. H3: Budaya organisasi berpengaruh positif dan signifikan terhadap kinerja karyawan dengan komitmen organisasi sebagai variable mediasi PT Tiki Jalur Nugraha Ekakurir (JNE) Jakarta

4. H4 : Budaya organisasi berpengaruh positif dan signifikan terhadap kepuasan karyawan PT Tiki Jalur Nugraha Ekakurir (JNE) Jakarta

5. H5: Komitment organisasi berpengaruh positif dan signifikan terhadap kinerja karyawan PT Tiki Jalur Nugraha Ekakurir (JNE) Jakarta

\section{METODOLOGI}

Peneltian ini dilakukan di perusahaan dalam bidang jasa yaitu PT Tiki Jalur Nugraha Ekakurir (JNE) Jakarta. Jumlah responden yang diteliti adalah 100 responden. Metode sampling yang akan digunakan dalam penelitian ini adalah non-probability sampling dengan jenis yang digunakan yaitu purposive sampling dengan pendekatan kuantitatif mengunakan kuisioner sebagai alat pengumpulan data. Analisis data yang digunakan Partial Least Square (PLS). 


\section{Hasil Uji Statistik}

Tabel 1. Average Variance Extracted

\begin{tabular}{|l|c|}
\hline & $\begin{array}{l}\text { Average Variance } \\
\text { Extracted (AVE) }\end{array}$ \\
\hline Budaya Organisasi & 0.580 \\
\hline Kepuasan kerja & 0.577 \\
\hline Komitment organisasional & 0.637 \\
\hline Kinerja karyawan & 0.601 \\
\hline
\end{tabular}

Tabel 2. (Korelasi antara Variabel Laten)

\begin{tabular}{|l|r|r|l|l|}
\hline & $\begin{array}{l}\text { Budaya } \\
\text { Organisasi }\end{array}$ & $\begin{array}{l}\text { Kepuasan } \\
\text { kerja }\end{array}$ & $\begin{array}{l}\text { Kinerja } \\
\text { Karyawan }\end{array}$ & $\begin{array}{l}\text { Komitmen } \\
\text { Organisasi }\end{array}$ \\
\hline $\begin{array}{l}\text { Budaya } \\
\text { Organisasi }\end{array}$ & 0,761 & & & \\
\hline $\begin{array}{l}\text { Kepuasan } \\
\text { kerja }\end{array}$ & 0,626 & 0,759 & & \\
\hline $\begin{array}{l}\text { Kinerja } \\
\text { Karyawan }\end{array}$ & 0,624 & 0,617 & 0,798 & \\
\hline $\begin{array}{l}\text { Komitmen } \\
\text { Organisasi }\end{array}$ & 0,607 & 0,618 & 0,564 & 0,775 \\
\hline
\end{tabular}

Tabel 3. Uji Reliabilitas

\begin{tabular}{|l|c|}
\hline & $\begin{array}{c}\text { Composite } \\
\text { Reliability }\end{array}$ \\
\hline Budaya organisasi & 0.892 \\
\hline Kepuasan kerja & 0.891 \\
\hline Kinerja karyawan & 0.913 \\
\hline Komitmen organisasi & 0.900 \\
\hline
\end{tabular}


Tabel 4. R-Square

\begin{tabular}{|l|c|c|}
\hline & R Square & $\begin{array}{l}\text { R Square } \\
\text { Adjusted }\end{array}$ \\
\hline $\begin{array}{l}\text { Kepuasan } \\
\text { Kerja }\end{array}$ & 0,392 & 0,386 \\
\hline $\begin{array}{l}\text { Kinerja } \\
\text { Karyawan }\end{array}$ & 0,491 & 0,475 \\
\hline $\begin{array}{l}\text { Komitmen } \\
\text { Organisasi }\end{array}$ & 0,368 & 0,362 \\
\hline
\end{tabular}

Tabel 5. Path Coefficients

\begin{tabular}{|c|c|c|c|c|c|}
\hline & $\begin{array}{c}\text { Original } \\
\text { Sample (O) }\end{array}$ & $\begin{array}{c}\text { Sample } \\
\text { Mean (M) }\end{array}$ & $\begin{array}{c}\text { Standard } \\
\text { Deviation } \\
\text { (STDEV) }\end{array}$ & $\begin{array}{c}\text { T Statistics } \\
(\mid \mathbf{O} / \text { STDE } \mid)\end{array}$ & P Values \\
\hline BO -> KK & 0,326 & 0,328 & 0,139 & 2,339 & $\mathbf{0 , 0 2 0}$ \\
\hline KE -> KK & 0,303 & 0,300 & 0,122 & 2,479 & $\mathbf{0 , 0 1 3}$ \\
\hline BO -> KO & 0,607 & 0,614 & 0,067 & 9,067 & $\mathbf{0 , 0 0 0}$ \\
\hline BO --> KK--> KO & 0.109 & 0.111 & 0.060 & 2.523 & $\mathbf{0 . 0 3 5}$ \\
\hline BO -> KE & 0,626 & 0,637 & 0,075 & 8,319 & $\mathbf{0 , 0 0 0}$ \\
\hline KO -> KK & 0,179 & 0,182 & 0,087 & 2,063 & $\mathbf{0 , 0 4 0}$ \\
\hline
\end{tabular}


Gambar 1. Hasil Uji Validitas Konvergen

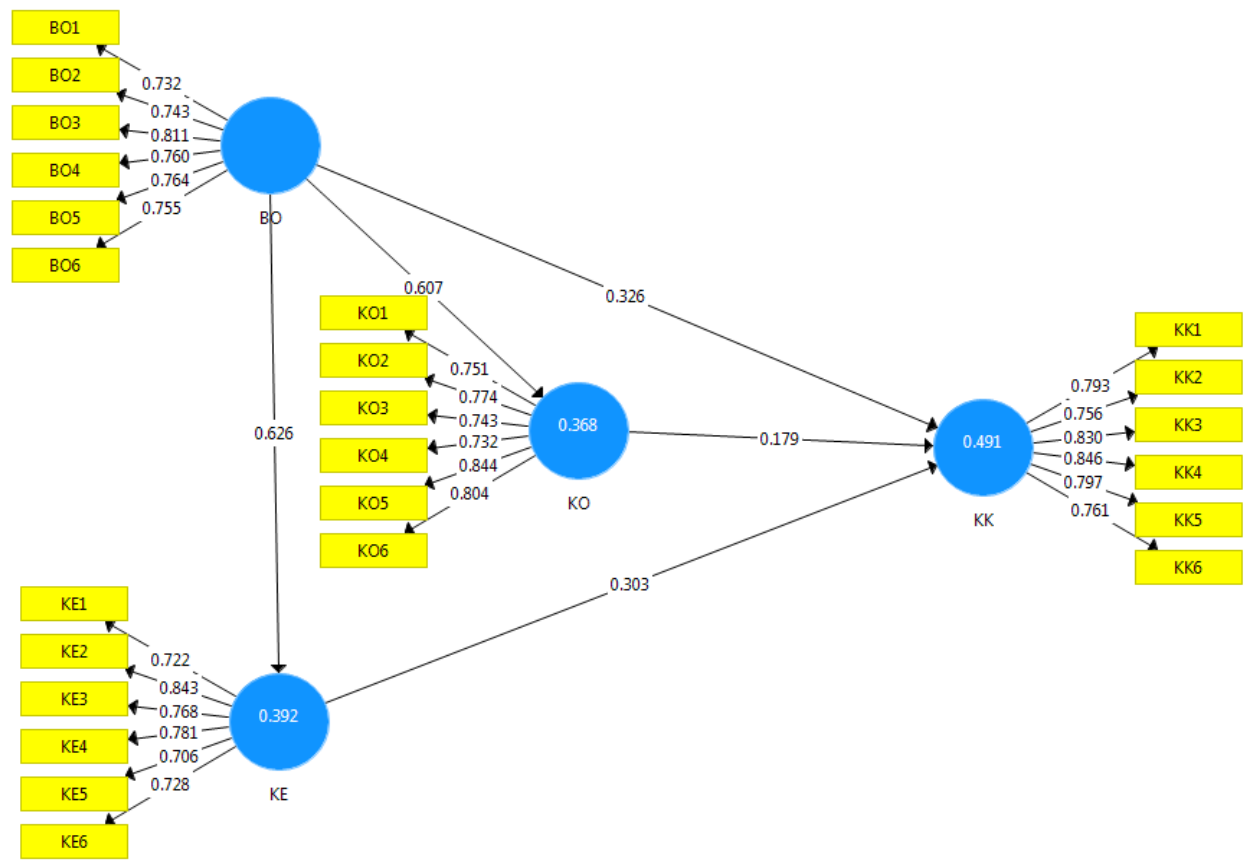

Gambar 2. Hasil Bootstrapping

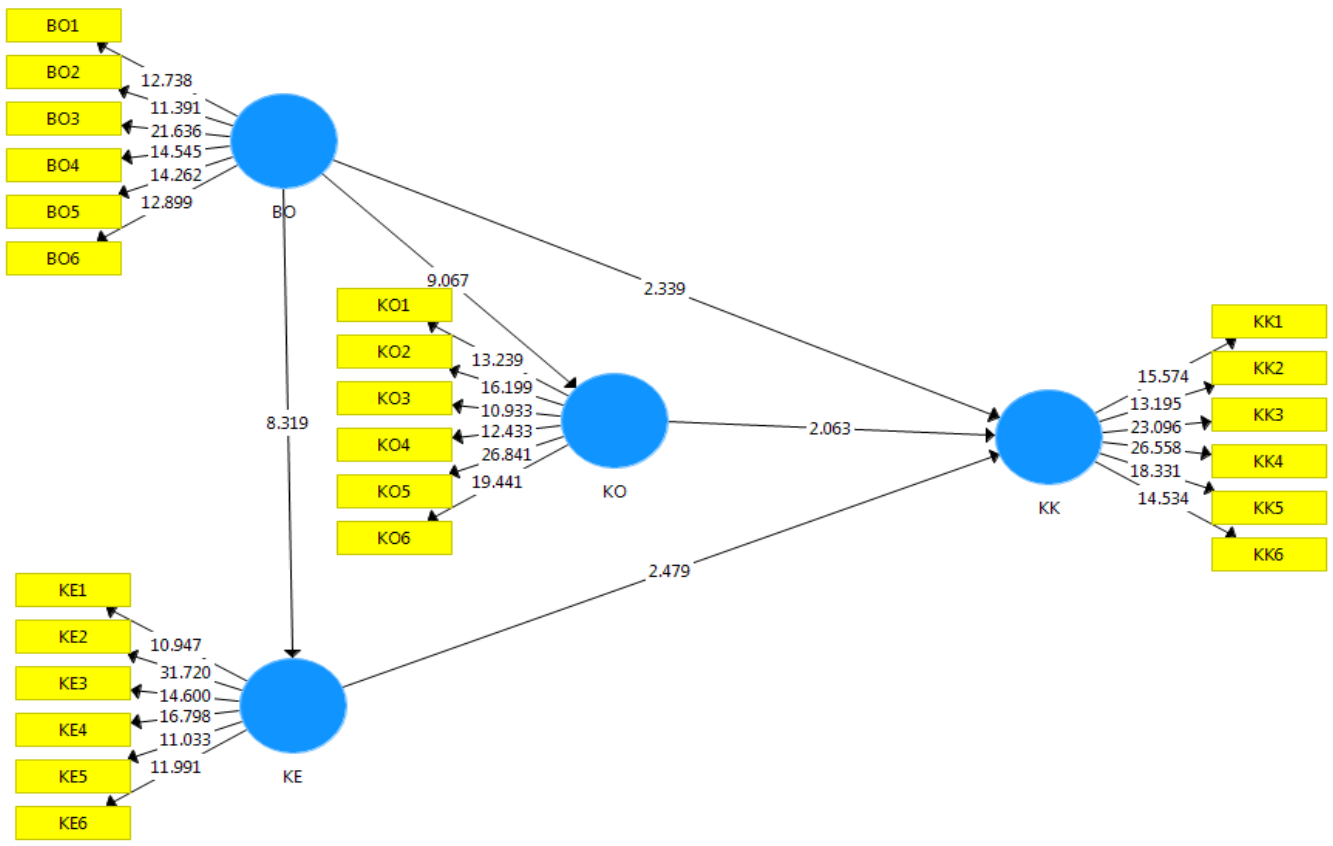




\section{DISKUSI}

Budaya organisasi mempunyai pengaruh yang signifikan terhadap kinerja karyawan PT Tiki Jalur Nugraha Ekakurir (JNE) Jakarta dengan nilai $t$ - statistics 2.339 yang berarti $>1.96$ dan nilai $\mathrm{P}$ values sebesar 0.020 apabila budaya organisasi meningkat maka akan terjadi peningkatan kinerja karyawan dan secara statistik memiliki pengaruh yang signifikan.

Kepuasan kerja mempunyai pengaruh yang signifikan terhadap kinerja karyawan PT Tiki Jalur Nugraha Ekakurir (JNE) Jakarta dengan nilai t - statistics 2.479 yang berarti $>1.96$ dan nilai $\mathrm{P}$ values sebesar 0.013 yang dapat diartikan lebih kecil dari 0,05 apabila karyawan dalam perusahan tersebut merasakan adanya kenyamanan saat mengerjaan pekerjaannya maka kinerja karyawan pun akan meningkat.

Budaya organisasi berpengaruh signifikan terhadap kinerja karyawan dengan komitmen organisasi sebagai variable mediasi PT Tiki Jalur Nugraha Ekakurir (JNE) Jakarta. dengan nilai $\mathrm{t} t$ - statistics 2,523 yang berarti $>1.96$ dan nilai $\mathrm{P}$ values sebesar 0.035 yang berarti bahwa budaya organisasi berpengaruh positif dan signifikan terhadap kinerja karyawan dengan komitmen organisasi sebagai variable mediasi PT Tiki Jalur Nugraha Ekakurir (JNE) Jakarta, artinya hipotesis ini menyatakan bahwa harus menerapkan nilai dan peraturan agar dapat mempengaruhi perilaku masing-masing karyawan karena dengan adanya hasrat untuk bekerja sama dalam sebuah organisasi maka, munculnya rasa komitment organisasi yang tinggi dalam diri karyawan masing-masing.

Budaya organisasi mempunyai pengaruh yang signifikan terhadap kepuasan kerja PT Tiki Jalur Nugraha Ekakurir (JNE) Jakarta dengan nilai $t$ - statistics 8.319 yang berarti $>1.96$ dan nilai $\mathrm{P}$ values sebesar 0.000 yang berarti bahwa budaya organisasi memiliki pengaruh positif dan signifikan terhadap kepuasan kerja apabila budaya organisasi terjalin dengan baik dalam perusahaan maka karyawan memperoleh kepuasan yang berada saat bekerja dan mempengaruhi kondisi kerja yang positif dan dinamis. Kondisi kerja yang dinamis dapat dilihat pada pekerjaan yang memberikan kesempatan bagi masing-masing individu untuk berfikir secara kreatif serta memiliki kebebasan untuk bekerja dan memiliki kontrol terhadap pekerjaan yang dilakukan.

Komitmen organisasi mempunyai pengaruh yang signifikan terhadap kinerja karyawan PT Tiki Jalur Nugraha Ekakurir (JNE) Jakarta dengan nilai t - statistics 2.063 yang berarti > 1.96 dan nilai $\mathrm{P}$ values sebesar 0.040 yang berarti bahwa komitmen organisasi memiliki pengaruh positif dan signifikan terhadap kinerja karyawan apabila seorang karyawan merasa bangga terhadap organisasi ditempat mereka bekerja maka, mereka dapat memberikan kontribusi dan berperan dalam mencapai tujuan organisasi yang akan terjalin dengan baik dalam perusahaan maka, kinerja karyawan pun akan meningkat.

\section{KESIMPULAN}

Berdasarkan penelitian yang telah dilakukan, penulis menyimpulkan sebagai berikut :

1. Budaya organisasi memiliki pengaruh positif dan signifikan terhadap kinerja karyawan.

2. Kepuasan kerja memiliki pengaruh positif dan signifikan terhadap kinerja karyawan. 
3. Budaya organisasi memiliki pengaruh tidak secara langsung yang positif dan signifikan terhadap kinerja karyawan dan komitmen organisasi sebagai variabel mediasi.

4. Budaya organisasi memiliki pengaruh positif dan signifikan terhadap kepuasan kerja.

5. Komitmen organisasi memiliki pengaruh positif dan signifikan terhadap kinerja karyawan.

Dalam penelitian ini saran yang akan diberikan dapat bermanfaat bagi perusahaan dan bagi peneliti lain, sebagai berikut :

1. Bagi perusahaan penelitian ini membahas mengenai budaya organisasi dan kepuasan kerja yang diterapkan dan dirasakan oleh masing-masing karyawan. Hasil penelitian menunjukan bahwa terdapat pengaruh yang postif dan signifikan pada masing-masing varibel. Penelitian ini menunjukkan bahwa rekan kerja saya memberikan dukungan yang cukup merupakan indikator yang paling rendah dalam variabel kepuasan kerja, maka dari itu perusahaan perlu meningkatkan kerjasama agar masing-masing karyawan dapat nyaman bekerja diperusahaan. Dan penerapan keselamatan kerja diperusahaan cukup baik merupakan indikator yang paling rendah dalam variabel budaya organisasi, dengan demikian perlu adanya keselamatan kerja yang pasti agar karyawan yang bekerja pun tetap merasa aman saat melakukan pekerjaannya karena perusahaan yang baik adalah perusahaan yang benar-benar menjaga keselamatan dan kesehatan karyawannya.

2. Bagi peneliti lain alangkah lebih baik apabila menambahkan variabel dalam melakukan penelitian terhadap kinerja karyawan sehingga terdapat gambaran yang lebih luas mengenai faktor-faktor apa saja yang dapat mempengaruhi kinerja karyawan

\section{DAFTAR PUSTAKA}

AA. Anwar Prabu Mangkunegara, (2013), Manajemen Sumber Daya Manusia Perusahaan, Remaja Rosdakarya, Bandung.

Kreitner, Robert dan Angelo Kinicki. (2014). Perilaku Organisasi. Edisi 9. Buku 1. Jakarta: Salemba Empat.

L. Mathis, Robert \& H. Jackson, John. (2011). Human Resource Managemen (edisi10). Jakarta : Salemba Empat.

Marta, O.E. and Suharnomo (2011), "Analisis pengaruh gaya kepemimpinan dan budaya.

Rivai, Veitzhal dan Mulyadi, Deddy. (2012). Kepemimpinan dan Perilaku.

Organisasi. Jakarta: PT Raja Grafindo Persada. 